\title{
Tetanus Immunisation In Hypersensitive Individuals
}

\author{
AN Williams, JBL Kabuubi, JP Owen, J Wells
}

\begin{abstract}
We report on a case of an officer cadet who was inadvertently allowed to commence training with a history suggestive of hypersensitivity to tetanus immunisation and who, eventually, successfully underwent a graduated immunisation regimen. This case combines a search for good evidence with the extraordinary complexities of military medical management and the law. It is a lesson in all three.
\end{abstract}

\section{Introduction}

The Armed Forces immunisation policy requires all recruits to have completed a full course of tetanus immunisation in accordance with the NHS regimen of five injections (1). This is a key occupational health requirement. Soldiers undergo regular arduous training over varied terrain that includes farmland and there is a significant risk of open wounds, combined with exposure to infection with Clostridium tetani.

As protection against tetanus relies on pre-

Lt Col A N William MFOM RAMC

Consultant in Occupational Medicine, Army Medical Directorate, Former Army Staff College, Slim Road, Camberley, Surrey, GU15 4NP.

Lt Col J B L Kabuubi FRCP RAMC

Consultant Physician, $\mathrm{MDHU}(\mathrm{N})$, Friarage Hospital, Northallerton, North Yorkshire, DL6 1JG.

\section{Lt Col J P Owen} MFOM RAMC

Consultant in Occupational Medicine, Army Medical Directorate, Former Army Staff College, Slim Road, Camberley, Surrey, GU15 4NP.

Col J Wells FRCGP RAMC

Commander Medical, HQ 2Division, Craigiehall, West Lothian EH30 9TN existing antibody levels, rather than an evoked memory response, it is necessary to maintain high resting antibody levels through a comprehensive vaccination programme. For recruits this involves immunisation at the time of the initial medical selection; refusal to immunise, or a history of hypersensitivity that prevents immunisation, is a bar to entry. The available literature suggests that, although a local reaction to tetanus is common, anaphylactic symptoms are extremely rare. Unfortunately, as with many other reactions, recruits tend to report 'allergies' to medication without any clear documented evidence of such.

\section{Case Report}

An officer cadet was inadvertently passed fit for entry into the Army at his Pre-Service medical examination, despite a history of a severe reaction to tetanus immunisation as a child. He had completed the initial three courses as an infant, and had a fourth preschool dose with no recorded adverse reaction. While on holiday aged 10 he injured himself and was given a booster dose to which he developed a 'severe local reaction'. $\mathrm{He}$ was not given the final school-leavers' dose.

Having uncovered the discrepancy at a routine review during initial officer training, the Medical Officer sent serum to check his immune status; the titration result (4产 units $/ \mathrm{ml}$ against a reference value of 64. units/ml, Birmingham Reference Labđ suggested that he had no protective immunity and so would require furthe $\vec{P}$ immunisation to continue military training He was referred, while still in training, to the local immunologist who conducte intradermal skin testing which produced a⿸尸 immediate wheal reaction. Thes immunologist stated that this was a generap indication of an increased risk o\$ anaphylactic reaction and recommended tha $\overrightarrow{\bar{\Phi}}$ immunisation should be conducted in a 'safe environment', i.e. a hospital which could deat with any anaphylactic reaction.

The officer cadet was therefore referred to a Service physician for immunisation; this physician refused to take the risk on the evidence presented, which complicated the matter as by then the officer cadet was tw weeks from completing his commissioning course. Further advice, sought from the Army's Civilian Consultant Adviser in Occupational Medicine, was that a refusal $b \vec{\varnothing}$ a consultant physician altered the leg situation and would require clear evidence te support a decision to immunise. On the other hand, there was considerable pressure from a variety of sources to allow the office cadet to 'pass out' from his training an continue to serve.

A full literature search was conducted an the manufacturer (Medeva Pharma) was consulted, as was the Medical Defence Union. There was significant evidence that true anaphylaxis to tetanus is very rare $(2 \delta$ Reported reactions include an immediate anaphylactoid reaction (3); a less frequer Arthus reaction and brachial neuritis are als $\overline{\bar{B}}$ reported (4). Department of Health (DoHP) advice (iv) states that 'an adverse reaction to tetanus toxoid does not preclude future immunisation with this same material. If th is to be done in patients with a history of a adverse reaction to a previous dose, then it best performed in a setting where there are facilities to deal with any acute allerg. reactions.'

The only significant study (5) individuals with reactions assessed 74 individuals with histories of reactions to tetanus. Seven hundred and thirty had negative skin prick tests and of the t positive individuals, four had immedia民 reactivity. Two of these four tolerated a full immunising dose without adverse effects; the 
Table 1. Incremental Immunisation Regimen and Observed Reactions

\begin{tabular}{|c|c|c|c|c|c|}
\hline $\begin{array}{l}\text { Inj } \\
\text { no. }\end{array}$ & $\begin{array}{c}\text { Vol } \\
(\mathrm{ml})\end{array}$ & Dilution & Route & $\begin{array}{l}\text { Observations } \\
\text { Immediate } \\
\text { Reaction }\end{array}$ & After 24 hrs \\
\hline 1 & 0.02 & $1: 1,000$ & Id & Nil & Nil \\
\hline 2 & 0.02 & $1: 100$ & Id & Nil & Nil \\
\hline 3 & 0.02 & $1: 10$ & Sc & Nil & Slight erythema \\
\hline 4 & 0.1 & $1: 10$ & Sc & Nil & Slight swelling \\
\hline 5 & 0.05 & Full & Sc & Nil & Swelling around site of inj \\
\hline 6 & 0.1 & Full & Sc & Nil & Swelling around site of inj \\
\hline 7 & 0.15 & Full & Sc & Nil & Swelling around site of inj \\
\hline 8 & 0.2 & Full & Sc & Nil & Swelling around site of inj \\
\hline
\end{tabular}

other two refused. Ninety-five patients had histories suggestive of prior anaphylactoid reaction and all tolerated full immunising doses. The advice from both $\mathrm{DoH}$ and US Department of Health and Human Services (DHHS) is that the only absolute contraindication to an immunising dose is a previous history of anaphylactic reaction and positive skin response. Furthermore, although there is a potential risk of a severe reaction from subsequent immunisation, this is so rare that a balance should be struck with the potential benefits. Somewhat frustratingly, the manufacturers advised that skin prick testing is now inappropriate because intradermal administration of the vaccine may give rise to a persistent nodule. However it was the skin prick testing that pointed to a possible anaphylactic risk, and started this lengthy process off.

Another case history was found describing an individual in the police, a high-risk occupation, with a previous history of immediate hypersensitivity reactions to tetanus toxoid; the history included loss of consciousness, difficulty in breathing and swelling of the face, arms and legs. Recent testing showed a lack of tetanus antibodies. In view of her desire to continue with her work in the police force, she elected to be immunised in a controlled environment. A graded dosing regimen was used to desensitise and immunise with minimal reaction and a good level of immunity was achieved (6).

Having found sufficient evidence to support a decision to immunise, another Army consultant physician was found who agreed to immunise. There followed the classic Service medical tale: the unit would not allow the newly commissioned officer to go to his appointment and he failed to attend. The physician then retired, the occupational physician was posted and the patient was then also posted. Eventually a new appointment was made with a new consultant and immunisation was undertaken nine months after commissioning.

In view of the history, it was decided to try the graded dose regimen reported by Uriel et al (6). Serum was taken for baseline levels of antibody and then a desensitisation process was undertaken as shown below:

a) Patient admitted, IV line established and bloods taken for FBC, U\&E, CRP, glucose, LFT, serum for tetanus antibodies.

b) Consent confirmed, resuscitation equipment prepared.

c) Immunisation commenced, with injections every 30 minutes over a four-hour period, using the regimen and making the observations, shown in Table 1.

d) Patient was kept in the hospital medical unit for 2 hours, before being transferred to a military primary care bed facility for overnight observation.

The first surprise was the result of the baseline antibody levels which at 1.9730 $\mathrm{iu} / \mathrm{ml}$ represented a significant antibody level, contrary to the original test. However as the original test followed a different analysis protocol, assaying the patient's sample against a reference population value, it is not possible to make direct comparisons with the ELISA protocol used subsequently. The final level was $4.2470 \mathrm{iu} / \mathrm{ml}$, a good protective level of immunisation.

\section{Conclusion}

Our conclusion from this tale is that individuals with a history of reaction to tetanus should be immunised before recruit entry; attempting to do so after entry can result in a considerable delay, and associated risk. The literature clearly demonstrates that genuine anaphylactic reaction to tetanus is very rare and even these individuals have been successfully immunised. Immunisation following a graded regimen is a safe and appropriate procedure for hypersensitive individuals at risk of tetanus infection. Where there has been a documented anaphylactic reaction, tetanus antibody levels should be taken and where there are protective levels immunisation should be deferred. Retesting at five-yearly intervals would be prudent.

\section{References}

1. Surgeon General Policy Letter 06/01 dated 31 Jan 01. Vaccination requirements for serving personnel in the Armed Forces. 
2. US DHHS MMWR Vol 45/N0. RR-12 30-1 dated 6 Sep 96.

3. Schroder JP, Kuhlmann WD. Avoidance of hyperergic reaction after booster tetanus toxoid vaccination. Lancet 1992; 340:379.

4. Immunisation Against Infectious Diseases. HMSO 1996.
5. Jacobs RL, Lowe RS, Lahier BQ. Adverse reactio $ᄃ$ to tetanus toxoid. $\mathscr{F} A M A$ 1982; $247: 40-4$.

6. Uriel AJ, Boyter AC, MacConnachie AM, Nathw D. Immunisation against tetanus, in a hypersensit individual, using a graded dosing regimen. 3 Infection 30(1): 83-84. 1995. 